\title{
The Utilization of Nitrogen Sources by Aspergillus clavatus
}

\author{
By J. H. ROBINSON, ${ }^{*}$ C. ANTHONY AND W. T. DRABBLE \\ Department of Physiology and Biochemistry, University of Southampton, \\ Southampton $\mathrm{SO}_{9}{ }_{3} \mathrm{TU}$
}

(Received 29 March $1974 ;$ revised 30 May 1974)

\begin{abstract}
SUMMARY
Ammonia, urea and glutamate are each used as sole nitrogen source by germinating conidia of Aspergillus clavatus. Ammonia is used preferentially when provided in the medium together with urea or glutamate. Germinated conidia actively transport glutamate against a concentration gradient. The suppression of glutamate utilization by ammonia is possibly mediated by an effect on the transport system for glutamate.
\end{abstract}

\section{INTRODUCTION}

Aspergillus clavatus is one of many micro-organisms which are being considered as potential sources of edible protein. In large-scale production of mycelium, ammonium salts or urea are commonly used as nitrogen source and $\mathrm{pH}$ control is achieved by periodic addition of ammonia gas. Ammonia represses the formation of several proteins involved in the nitrogen metabolism of Aspergillus nidulans (Cove, 1966; Darlington \& Scazzocchio, 1967; Arst \& Cove, 1969; Cohen, 1972) and both represses and inhibits the active transport system for acidic amino acids (Robinson, Anthony \& Drabble, 1973a,b). It is thus possible that using ammonia for $\mathrm{pH}$ control may prevent efficient utilization of major nitrogen sources and of supplementary nitrogen compounds such as amino acids. Many fungi, including species of Aspergillus (Nicholas, 1958), use ammonia in preference to nitrate as nitrogen source. We now show that ammonia is used in preference to urea and glutamate and that the utilization of ammonia in preference to glutamate may involve regulation of the active transport system for glutamate in $A$. clavatus.

\section{METHODS}

Organism. A culture of A. clavatus Desm. was obtained from Rank Hovis McDougall (Research) Ltd, High Wycombe, Buckinghamshire. Its identity was confirmed by the Commonwealth Mycological Institute, Kew, Surrey. This strain was assigned the number IMI 137268.

Growth media, chemicals, preparation of conidia and extraction of intracellular amino acids. These are as described previously (Robinson et al. 1973a,b).

Germination of conidia. Conidia (approx. ${ }_{10}^{7} / \mathrm{ml}$ medium) were incubated in growth medium at $30{ }^{\circ} \mathrm{C}$ in baffled conical flasks on a gyrotary shaker. Unless otherwise stated, the conidia were germinated until germ tubes were just visible in more than $80 \%$ of conidia (usually 10 to $\mathrm{I} 2 \mathrm{~h}$ after inoculation). For preparation of standard suspensions prior to

* Present address: Department of Hormone Biochemistry, Imperial Cancer Research Fund, Lincoln's Inn Fields, London. 
further growth in various media, the germinated conidia were aseptically harvested by centrifugation ( $18000 \mathrm{~g}$ for Io $\mathrm{min}$ ) and washed with, and resuspended in, sterile saline.

Growth of germinated conidia. Germinated conidia prepared as described above were aseptically transferred (approx. $10^{7}$ germinated conidia $/ \mathrm{ml}$ ) to fresh medium and incubated as described for germination of conidia. The turbidity of cultures was used as a measure of growth. Samples were withdrawn from culture vessels and homogenized in the growth medium for about Io $\mathrm{s}$ with a Teflon homogenizer. The extinction of the resulting suspension was measured at $600 \mathrm{~nm}$, with growth medium as reference.

Assay of ammonia, urea and glutamate. Ammonia was assayed by micro-diffusion followed by reaction with ninhydrin (Conway, 1950).

Urea was estimated by the condensation reaction with diacetylmonoxime. Urea solution ( $\mathrm{I} \cdot 0 \mathrm{ml}$ ) was mixed with $0.5 \mathrm{ml}$ hydroxylamine $(0.2 \%), 0.5 \mathrm{ml}$ diacetyl $(0.2 \%)$ and $\mathrm{I} \cdot 0 \mathrm{ml}$ $\mathrm{H}_{2} \mathrm{SO}_{4}-\mathrm{H}_{3} \mathrm{PO}_{4}$ mixture (I vol. conc. $\mathrm{H}_{2} \mathrm{SO}_{4}: 3$ vol. syrupy $\mathrm{H}_{3} \mathrm{PO}_{4}$ ). The mixture was heated at $100{ }^{\circ} \mathrm{C}$ for $45 \mathrm{~min}$ in the dark and estimated by measurement of the extinction at $470 \mathrm{~nm}$.

Glutamate was assayed enzymically using L-glutamic dehydrogenase and 3-acetylpyridine $\mathrm{NAD}^{+}$(Kaplan, Ciotti \& Stolzenbach, 1956).

Measurement of uptake of $\mathrm{L}-\left[U_{-}{ }^{14} C\right]$ glutamate. Samples were removed from the cultures with a wide-bore $10 \mathrm{ml}$ pipette, filtered under vacuum on to Whatman No. I filter paper circles ( $13 \mathrm{~mm}$ diam) and washed twice with $\mathrm{I} 0 \mathrm{ml}$ volumes of warm $\left(30^{\circ} \mathrm{C}\right)$, nitrogen-free medium. The filter disc, with sample attached, was added to a test tube containing 2 or $4 \mathrm{ml}$ medium (at $30^{\circ} \mathrm{C}$ and $\mathrm{pH} 6.5$ ) and an appropriate concentration of radioactive compound. The mycelium was freed from the filter disc using a Rotamixer and the medium with suspended mycelium was aerated by vigorously shaking the test tube in a $30{ }^{\circ} \mathrm{C}$ water bath. Samples $(0.5 \mathrm{ml} ; 0.1$ to $0.5 \mathrm{mg}$ dry wt) were taken with a wide-bore, I ml pipette at suitable intervals. Each sample was filtered under vacuum on to $13 \mathrm{~mm}$ diam Whatman No. I filter paper and washed twice with Io $\mathrm{ml}$ volumes of ice-cold distilled water. The filter disc was air dried (at room temperature for $12 \mathrm{~h}$ ), and placed in glass scintillation vials with $10 \mathrm{ml}$ scintillation fluid [8 $\mathrm{g}$ butyl-PBD/l, dissolved in toluene-methanol $(3: \mathrm{I})$ ]. Samples were counted for two 5 min periods in a Beckman Model CPM200 scintillation counter. Under the conditions used, quenching of the radioactivity was approximately the same in every sample, and never exceeded $10 \%$ of the total radioactivity. A large sample of the germinated conidia was weighed and dried at $105^{\circ} \mathrm{C}$ to constant weight. From the wet weight to dry weight ratio of this sample the dry weights of the samples used in the assays were calculated. The amount of substrate transported by the conidia during the first 3 min of assay was calculated from the total radioactivity associated with the germinated conidia and the known specific activity of the substrate. The rate of transport was proportional to dry weight up to $\mathrm{I} \cdot 2 \mathrm{mg}$.

\section{RESULTS}

\section{Utilization of ammonia in preference to urea as nitrogen source}

Ammonia is used in preference to urea during the germination period (Fig. I $a$ ). After germination on uric acid, urea could be used immediately as sole nitrogen source for further growth but ammonia prevented this (Fig. $\mathrm{I} b$ ). The rate of urea utilization increased sevenfold after exhaustion of ammonia from the growth medium but decreased after addition of further ammonium sulphate. Thus, ammonia prevents urea utilization during germination and also at a later stage of growth even after adaptation to growth with urea as sole nitrogen source. 

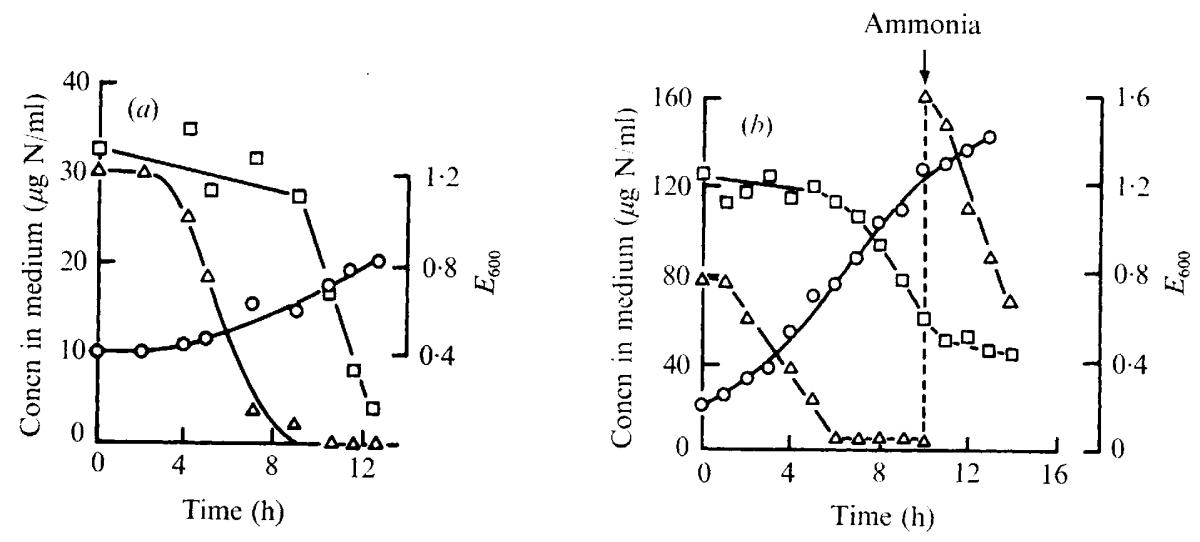

Fig. I. Utilization of ammonia in preference to urea. $\square$, Concentration of urea in medium; $\triangle$, concentration of ammonia in medium; $\bigcirc$, extinction of homogenized culture at $600 \mathrm{~nm}$. (a) During germination. Conidia (about $3 \times 10^{7} / \mathrm{ml}$ ) were germinated at $30^{\circ} \mathrm{C}$ in medium containing urea and ammonia. (b) During growth. Conidia germinated for $12 \mathrm{~h}$ at $30^{\circ} \mathrm{C}$ in uric acid medium $(75 \mu \mathrm{g}$ $\mathrm{N} / \mathrm{ml}$ ) were harvested, washed, and resuspended in medium containing urea and ammonia. After incubation at $30{ }^{\circ} \mathrm{C}$ for $10 \mathrm{~h}$ ammonia was added to the medium (arrow).
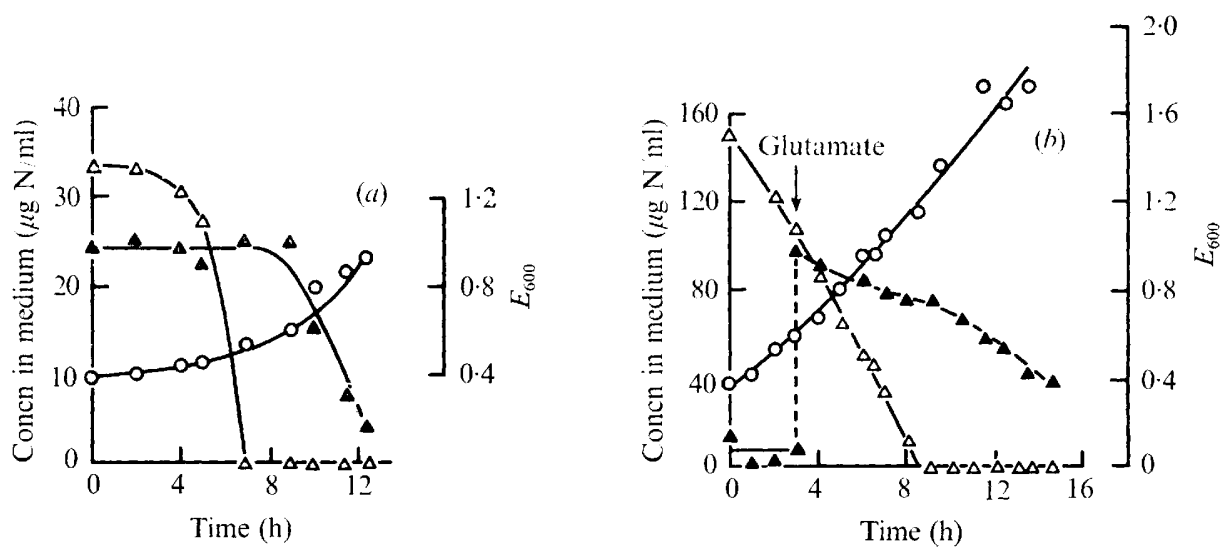

Fig. 2. Utilization of ammonia in preference to glutamate. $\boldsymbol{\Lambda}$, Concentration of glutamate in medium; $\triangle$, concentration of ammonia in medium; $O$, extinction of homogenized culture at $605 \mathrm{~nm}$. (a) During germination. Conidia (about $3 \times 10^{7} / \mathrm{ml}$ ) were germinated at $30^{\circ} \mathrm{C}$ in medium containing glutamate and ammonia. (b) During growth. Conidia germinated for $\mathrm{I} 2 \mathrm{~h}$ at $30^{\circ} \mathrm{C}$ in medium with urea $(60 \mu \mathrm{g} \mathrm{N} / \mathrm{ml})$ and glutamate $(60 \mu \mathrm{g} \mathrm{N} / \mathrm{ml})$ as nitrogen sources were harvested, washed and resuspended (about $10^{7}$ conidia $/ \mathrm{ml}$ ) in ammonia medium. After $3 \mathrm{~h}$ incubation at $30^{\circ} \mathrm{C}$ glutamate was added to the medium (arrow).

\section{Utilization of ammonia in preference to glutamate as nitrogen source}

During germination ammonia was used before glutamate (Fig. $2 a$ ). By contrast, urea and glutamate were used simultaneously, and after germination on this mixture glutamate was used immediately as sole nitrogen source for further growth. When ammonia was included with glutamate during this period of further growth the rate of glutamate utilization was low (Table I). This low rate was also observed after addition of glutamate to a culture growing on ammonia (Fig. $2 b$ ). After exhaustion of the ammonia from the medium the rate of glutamate utilization increased to that observed when glutamate was the sole source of nitrogen for growth (Table I). 
Table I. Rates of utilization of nitrogen sources from the medium during growth of germinated conidia of A. clavatus

Rates of utilization are expressed as $\mu \mathrm{g} \mathrm{N} / \mathrm{h} / \mathrm{ml}$ culture. The rates given in parentheses are those measured after complete exhaustion of ammonia from the growth medium.

Nitrogen source(s)

in growth medium

Ammonia

Glutamate

Urea

Glutamate + ammonia

Urea + ammonia

Rates of utilization of nitrogen source

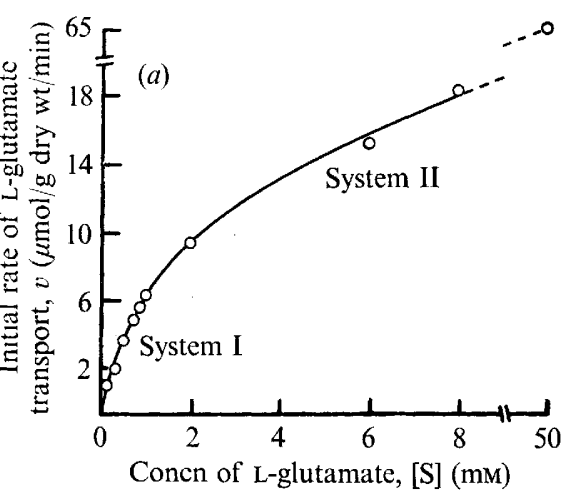

\begin{tabular}{ccc}
\hline Ammonia & Glutamate & Urea \\
16 & - & - \\
- & 8 & - \\
19 & - & II \\
17 & $-5(8 \cdot 0)$ & -
\end{tabular}

Fig. 3. Kinetics of glutamate transport in germinated conidia of $A$. clavatus. (a) Direct plot; (b) data plotted as reciprocals. Conidia germinated for $12 \mathrm{~h}$ at $30^{\circ} \mathrm{C}$ in uric acid medium $(75 \mu \mathrm{g} \mathrm{N} / \mathrm{ml})$ were harvested, washed and resuspended (about $10^{7}$ germinated conidia/ml) in glutamate (10 $\mathrm{mm}$ ) medium. After $4 \mathrm{~h}$ incubation at $30^{\circ} \mathrm{C}$ the germinated conidia were harvested by filtration, and transport of $\mathrm{L}-\left[\mathrm{U}-{ }^{14} \mathrm{C}\right]$ glutamate was measured as described in Methods.

\section{Rates of utilization of nitrogen sources}

The growth rates on all nitrogen sources used in this work were the same. The rates of utilization of nitrogen sources for growth of germinated conidia are summarized in Table I. The rate of ammonia utilization was not significantly affected by the presence of urea or of glutamate in the growth medium. Ammonia, however, decreased the rates of utilization of urea and glutamate to $16 \%$ of the rates measured in its absence. Ammonia might exert its effect by inhibiting either the synthesis or the activity of membrane transport systems or of enzymes responsible for nitrogen metabolism (or both). The following results suggest that ammonia may exert at least part of its effect on glutamate utilization by affecting the transport of glutamate in A. clavatus.

\section{Transport of $\mathrm{L}-\left[U_{-}{ }^{14} C\right]$ glutamate by germinated conidia of $A$. clavatus}

In all the experiments described below the transport of $\mathrm{L}$-glutamate was measured using 0.1 to $0.5 \mathrm{mg}$ dry wt of germinated conidia over a period of $3 \mathrm{~min}$. After $3 \mathrm{~min}$, more than $90 \%$ of the intracellular radioactivity was found in compounds soluble in $5 \%$ tricarboxylic acid. This result implies that less than $10 \%$ of the glutamate was incorporated into protein during the 3 min assay period. 


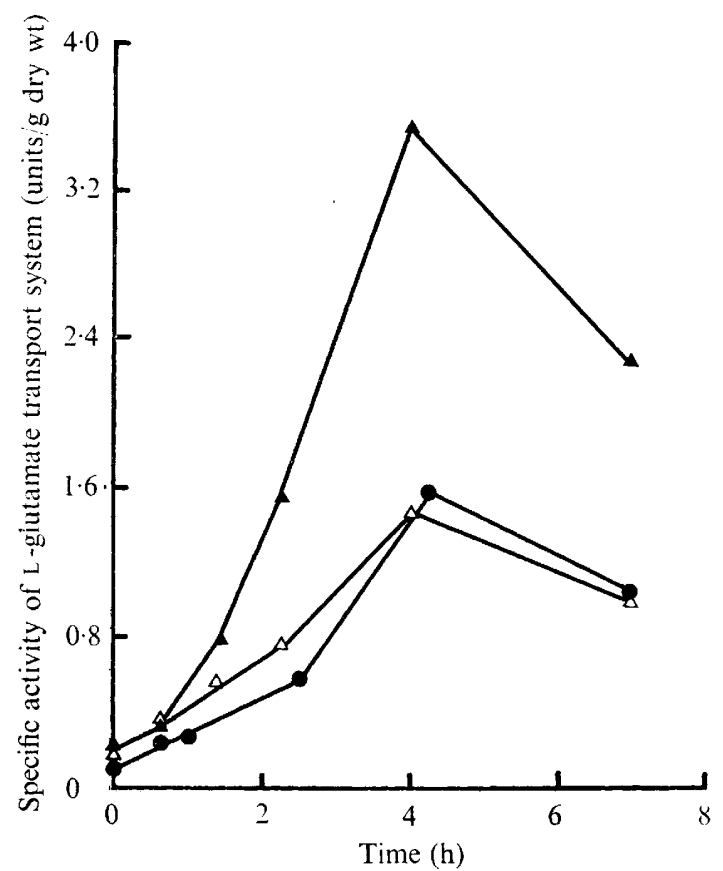

Fig. 4. Activity of the glutamate transport system after growth of germinated conidia on various nitrogen sources. Conidia germinated for $12 \mathrm{~h}$ at $30^{\circ} \mathrm{C}$ in uric acid medium $(75 \mu \mathrm{g} \mathrm{N} / \mathrm{ml})$ were harvested, washed, resuspended $\left(\mathrm{IO}^{7}\right.$ germinated conidia $\left./ \mathrm{ml}\right)$ in various growth media and incubated at $30^{\circ} \mathrm{C}$. One unit of glutamate transport activity is defined as the rate of transport of $1 \mu \mathrm{mol}$ substrate/min at $30{ }^{\circ} \mathrm{C}$ and $\mathrm{pH} \mathrm{6.5}$. Nitrogen sources of the growth media: $\Delta$, glutamate (IO mM); 0 , ammonium sulphate $(5 \mathrm{mM}) ; \triangle$, glutamate (IO mM) plus ammonium sulphate $(5 \mathrm{mM})$.

Kinetics of glutamate transport by germinated conidia. The initial rate of glutamate transport varied with the concentration of glutamate in the assay medium (Fig. 3). The biphasic nature of the graphs indicate that there are two 'systems' for glutamate transport differing in their affinities for glutamate. System I has a high affinity with an apparent $K_{m}$ of I. $33 \mathrm{~mm}$ and a $V_{\max }$ of $13.9 \mu \mathrm{mol} / \mathrm{g}$ dry wt $/ \mathrm{min}$. System II has a low affinity for glutamate. The transport of glutamate measured at low concentrations in the experiments described below is mediated by system I. The $K_{m}$ value given above is an apparent $K_{m}$ value, because it may be determined not only by the binding of substrate to the permease but also by other rate-limiting steps in transport across the membrane and by intracellular metabolism of the substrate.

Transport of glutamate against a concentration gradient by an energy-requiring process. The pool size of glutamate (determined by enzymic assay of extracts of germinated conidia) was $27 \mathrm{mM}$ in conidia germinated with uric acid and $30 \mathrm{~mm}$ in the same conidia grown for a further $4.5 \mathrm{~h}$ in glutamate medium. Thus, $\mathrm{I} \cdot 0 \mathrm{~mm}$-glutamate (the concentration used in assay of transport) was transported against a concentration gradient of $\mathrm{I}: 30$. This transport was greatly diminished under anaerobic conditions, did not occur at $2{ }^{\circ} \mathrm{C}$ and was $90 \%$ inhibited by $\mathrm{I} \cdot 0 \mathrm{~mm}$-azide. This inhibition occurred in germinated conidia and also in the same conidia after growth for a further 4 or $24 \mathrm{~h}$ in glutamate medium. 


\section{Activity of the glutamate permease after growth on ammonia or glutamate as nitrogen source}

Glutamate permease was measured in conidia, germinated with uric acid, and transferred to media in which the nitrogen source was either glutamate, ammonia or glutamate + ammonia (Fig. 4). After growth with glutamate alone there was an 18 -fold increase in glutamate permease activity. The increase in activity was less than half this amount when ammonia was present (whether or not glutamate was also present).

\section{DISCUSSION}

Ammonia is used in preference to either urea or glutamate as nitrogen source for germination and growth of $A$. clavatus. This preferred utilization of ammonia may involve the system for transport of glutamate, the activity of which is reduced when germinated conidia are grown with ammonia (even in the presence of glutamate). Ammonia does not inhibit the permease when present in the assay medium; it must therefore exert its effect by inhibition from within the organism or by repression of synthesis of the permease. Both of these mechanisms have recently been shown to operate in the regulation of the acidic amino acid permease of $A$. nidulans (Robinson et al. $1973 b$ ).

We thank Professor K. A. Munday for his encouragement in this work and Rank Hovis McDougall (Research) Ltd for financial assistance.

\section{REFERENCES}

Arst, H. N. \& Cove, D. J. (1969). Methylammonium resistance in Aspergillus nidulans. Journal of Bacteriology $98, \mathrm{I} 284-1293$.

COHEN, B. L. (1972). Ammonium repression of extracellular protease in Aspergillus nidulans. Journal of General Microbiology 7r, 293-299.

ConWAY, E. J. (1950). In Microdiffusion Analysis and Volumetric Error. London: Crosby, Lockwood.

Cove, D. J. (1966). The induction and repression of nitrate reductase in the fungus Aspergillus nidulans. Biochimica et biophysica acta $\mathbf{1} 3,5 \mathrm{I}-56$.

Darlington, A. J. \& SCAzzocchio, C. (1967). Use of analogues and the substrate-sensitivity of mutants in analysis of purine breakdown in Aspergillus nidulans. Journal of Bacteriology 93, 937-940.

Kaplan, N. O., Ciotti, M. M. \& Stolzenbach, F. E. (I956). Reaction of pyridine nucleotide analogues with dehydrogenases. Journal of Biological Chemistry 22x, 833-844.

Nicholas, D. J. D. (1958). Utilisation of inorganic nitrogen compounds and amino acids by fungi. In $P$ hysiology of Fungi, pp. 349-376. Edited by V. W. Cochrane. New York; John Wiley.

Robinson, J. H., Anthony, C. \& Drabble, W. T. (I973a). The acidic amino acid permease of Aspergillus nidulans. Journal of General Microbiology 79, 53-63.

Robinson, J. H., Anthony, C. \& Drabbie, W. T. (1973 $b$ ). Regulation of the acidic amino acid permease of Aspergillus nidulans. Journal of General Microbiology 79, 65-80. 